\title{
Distribution of biotypes of Haemophilus influenzae and $H$ parainfluenzae in patients with cystic fibrosis
}

\author{
KC WATSON, EJC KERR, CA HINKS \\ From the Central Microbiological Laboratories, Western General Hospital, Edinburgh
}

SUMMARY One hundred and eighty eight isolates of Haemophilus influenzae and 187 isolates of $H$ parainfluenzae from patients with cystic fibrosis, patients with respiratory infections but without cystic fibrosis, and patients with neither cystic fibrosis nor respiratory infections were biotyped. Biotype I of $H$ influenzae were found significantly more often in patients with cystic fibrosis compared with those with normal respiratory tracts. On the other hand, biotype II strains of $H$ influenzae were found less often in the cystic fibrosis group. Half of the biotype $\mathrm{V}$ strains produced $\beta$-lactamase.

Biotyping of strains of the genus Haemophilus has been carried out extensively in recent years according to a scheme devised by Kilian.' The method has been applied as an epidemiological tool ${ }^{2}$ and correlations have been established between biotypes, serotypes, antibiotic sensitivity, and site of isolation. ${ }^{34}$

In view of the importance of Haemophilus influenzae as a respiratory pathogen in cystic fibrosis we undertook biotyping of strains of $H$ influenzae and $H$ parainfluenzae in a group of such patients and compared the results with isolates from patients with respiratory tract infections but without cystic fibrosis and a further group of patients in hospital with neither respiratory infections nor cystic fibrosis.

\section{Patients and methods}

ORGANISMS

Gram negative organisms corresponding to the general description of the genus Haemophilus were isolated on standard chocolate agar plates supplemented with $10 \mathrm{IU} / \mathrm{ml}$ of bacitracin.

\section{PATIENTS}

There were 179 patients in the cystic fibrosis group (group 1), 110 in the respiratory infection group (group 2), and 73 in the group with no respiratory infection (group 3). A total of 183 separate isolates were tested from group 1,118 from group 2, and 74

Accepted for publication 14 March 1985 from group 3. Groups 1 and 2 isolates were all from the respiratory tract. Group 3 isolates included 61 from throat swabs; two each from cerebrospinal fluid, umbilical swabs, ear swabs, and urine; four isolates from eye swabs; and one from a blood culture.

\section{$X$ AND V FACTOR}

$\mathrm{X}$ and $\mathrm{V}$ factor requirements were determined with discs on Columbia agar base medium according to standard techniques. In addition, the requirement for $\mathrm{X}$ factor was tested by the ability of isolates to synthesise porphyrins from $\delta$-amino-laevulinic acid. ${ }^{5}$ Strains designated as $H$ influenzae in the text are those that were $\mathrm{V}$ factor dependent and incapable of converting $\delta$-amino-laevulinic acid to porphyrins. On the basis of these criteria there were 188 isolates of $H$ influenzae, with 82,64 , and 42 in groups 1,2 , and 3, respectively. There were 187 strains of $H$ parainfluenzae, comprising 101,54 , and 32 in groups 1,2 , and 3 , respectively.

\section{BIOTYPES}

Biotyping was carried out with API 10 S strips to test for indole production, ability to split urea, and production of ornithine decarboxylase and $\beta$-galactosidase. The organisms were emulsified in $3.0 \mathrm{ml}$ of peptone water supplemented with $0.3 \mathrm{ml}$ of $1.0 \%$ haemin and $0.3 \mathrm{ml}$ of $\beta$-nicotinamide adenine dinucleotide. Strips were incubated overnight at $37.0^{\circ} \mathrm{C}$ after addition of liquid paraffin to the indole cupule. Indole was detected with Erlich's reagent. The purity of the inoculums was checked by plating on to standard chocolate agar plates. 
Table 1 Biotypes of 188 strains of Haemophilus influenzae

\begin{tabular}{|c|c|c|c|c|}
\hline \multirow[t]{2}{*}{ Biotype } & \multicolumn{4}{|c|}{ Patient group (no and (\%)) } \\
\hline & 1 & 2 & 3 & Total \\
\hline $\begin{array}{l}\text { I } \\
\text { II } \\
\text { III } \\
\text { IV } \\
\text { V } \\
\text { NT } \\
\text { Total }\end{array}$ & $\begin{array}{r}24(29) \\
19(23) \\
10(12) \\
8(10) \\
13(16) \\
8(10) \\
82\end{array}$ & $\begin{array}{c}15(23) \\
20(31) \\
11(17) \\
4(6) \\
11(17) \\
3(5) \\
64\end{array}$ & $\begin{array}{r}8(19) \\
18(43) \\
8(19) \\
2(5) \\
6(14) \\
0(0) \\
42\end{array}$ & $\begin{array}{r}47 \\
57 \\
29 \\
14 \\
30 \\
11 \\
188\end{array}$ \\
\hline
\end{tabular}

Group 1 = patients with cystic fibrosis.

Group 2 = patients with respiratory infections.

Group $3=$ control group.

$\%$ figures refer to percentage of that biotype related to total of all biotypes for that group.

NT $=$ not typeable.

Table 2 Biotypes of 187 strains of Haemophilus parainfluenzae

\begin{tabular}{|c|c|c|c|c|}
\hline \multirow[t]{2}{*}{ Biotype } & \multicolumn{4}{|c|}{ Patient group ${ }^{*}$ (no and (\%)) } \\
\hline & 1 & 2 & 3 & Total \\
\hline $\begin{array}{l}\text { I } \\
\text { II } \\
\text { III } \\
\text { IV } \\
\text { NT } \\
\text { Total }\end{array}$ & $\begin{array}{c}26(26) \\
43(42) \\
20(20) \\
10(10) \\
2(2) \\
101\end{array}$ & $\begin{array}{c}20(37) \\
23(43) \\
3(5) \\
8(15) \\
0(0) \\
54\end{array}$ & $\begin{array}{c}12(37) \\
12(37) \\
6(19) \\
1(3) \\
1(3) \\
32\end{array}$ & $\begin{array}{r}58 \\
78 \\
29 \\
19 \\
3 \\
187\end{array}$ \\
\hline
\end{tabular}

${ }^{*}$ See footnote to Table 1 .

\section{SEROTYPING}

Capsulated strains were detected by standard methods using rabbit antisera (Wellcome Reagents).

\section{Results}

\section{DISTRIBUTION OF BIOTYPES}

Table 1 shows that within the cystic fibrosis group $H$ influenzae biotype 1 predominated and occurred significantly more often than similar isolates from the normal respiratory tracts of group 3 patients ( $p$ $=<0.05)$. Biotype II is also of interest in that there appears to be a negative correlation between cystic fibrosis and the occurrence of this biotype when compared with similar isolates from normal respiratory tracts $(p=<0 \cdot 01)$. No significant differences in biotype distributions were noted in the case of $\boldsymbol{H}$ parainfluenzae strains in the three groups (Table 2).

\section{COMPARISON OF PORPHYRIN SYNTHESIS AND X} AND V TESTS

Of the total of 375 strains of Haemophilus examined, 336 gave agreement between $X$ and $V$ tests and the ability to synthesise porphyrins from $\delta$-amino-laevulinic acid. Thirty four strains, however, would have been designated as $H$ parainfluenzae on the basis of $\mathrm{X}$ and $\mathrm{V}$ results but failed to synthesise porphyrins, representing $18 \%$ of all true
$H$ influenzae isolates. Table 3 shows distribution of the biotypes of these $34 \mathrm{H}$ influenzae strains.

Only five strains which were found to synthesise porphyrins would have been wrongly classified as $H$ influenzae on the results of $\mathrm{X}$ and $\mathrm{V}$ tests. If the figures for each biotype in Table 3 are considered as a percentage of the total numbers in each biotype as indicated in Table 1 they represent $14 \cdot 8,22 \cdot 8,10 \cdot 3$, $28 \cdot 5$, and $20 \%$ for biotypes $I$ to $V$ respectively.

\section{$\beta$-LACTAMASE PRODUCTION AND BIOTYPES}

Table 4 shows the relation between biotype and $\beta$-lactamase production. No fewer than $23.5 \%$ of $H$ influenzae strains were $\beta$-lactamase producers compared with $7.4 \%$ for $H$ influenzae isolates. Half of the $\beta$-lactamase positive strains of $H$ influenzae were

Table 3 Distribution of Haemophilus influenzae strains giving anomalous $X$ and $V$ test results

\begin{tabular}{lllllll}
\hline $\begin{array}{l}\text { Patient } \\
\text { group }\end{array}$ & \multicolumn{5}{l}{ No in each biotype } \\
\cline { 2 - 7 } & $I$ & $I I$ & III & IV & $V$ & NT \\
\hline 1 & 1 & 5 & 1 & 2 & 2 & 0 \\
2 & 4 & 3 & 1 & 2 & 3 & 1 \\
3 & 2 & 5 & 1 & 0 & 1 & 0 \\
\hline
\end{tabular}

Figures represent the number of isolates that gave negative porphyrin tests but which have been classified as Haemophilus parainfluenzae on the basis of $\mathrm{X}$ and $\mathrm{V}$ test results.

* See footnote to Table 1. 
Table $4 \quad \beta$-lactamase production of biotypes of Haemophilus infuenzae and $H$ parainfuenzae

\begin{tabular}{|c|c|c|c|c|c|c|c|c|}
\hline \multirow{2}{*}{$\begin{array}{l}\text { Patient } \\
\text { group * }\end{array}$} & \multirow[t]{2}{*}{ Isolates } & \multirow{2}{*}{$\begin{array}{l}\beta \text {-lactamase } \\
\text { positive (\%) }\end{array}$} & \multicolumn{6}{|c|}{ No in each biotype } \\
\hline & & & $\bar{I}$ & II & III & $I V$ & $V$ & $N T$ \\
\hline \multicolumn{9}{|c|}{$H$ infuenzae } \\
\hline 1 & 82 & $5(6)$ & 1 & 1 & 0 & 0 & 3 & 0 \\
\hline 2 & 64 & $6(9 \cdot 3)$ & 1 & 1 & 1 & 1 & 2 & 0 \\
\hline 3 & 42 & $3(7 \cdot 1)$ & 0 & 1 & 0 & 0 & $\overline{2}$ & 0 \\
\hline \multicolumn{9}{|c|}{$H$ parainfuenzae } \\
\hline 1 & 101 & $30(30)$ & 13 & 12 & 3 & 2 & - & 0 \\
\hline 2 & 54 & $8(14 \cdot 8)$ & 3 & 3 & 1 & 1 & - & 0 \\
\hline 3 & 32 & $6(18 \cdot 7)$ & 3 & 2 & 1 & 0 & - & 0 \\
\hline
\end{tabular}

${ }^{*}$ See footnote to Table 1 .

of biotype V. These seven strains represent $23.3 \%$ of all biotype $\mathrm{V}$ isolates. No differences were noted in the incidence of positive isolates in the three groups of patients.

\section{DISTRIBUTION OF SEROTYPES AND BIOTYPES OF H INFLUENZAE}

Capsule production was tested for in 152 of the 188 strains of $H$ influenzae. Table 5 shows the distribution of the biotypes and serotypes of the 31 capsulated strains. Fifteen of the $41(36.5 \%)$ biotype I strains were capsulated, most being of type b. Only $15.4 \%$ of biotype II strains were capsulated, with corresponding small percentages for the remaining biotypes.

\section{Discussion}

$H$ influenzae of biotypes I and II are those most often isolated from septicaemic and meningitic illnesses, although geographical differences probably exist. Biotype III strains are the most common in Taiwan, ${ }^{8}$ and biotype $\mathrm{V}$ comprised $9 \%$ of isolates from cerebrospinal fluid and $25 \%$ of blood isolates in New York State. ${ }^{3}$ Biotypes II and III predominated in conjunctival isolates and also occurred among urinary tract strains. ${ }^{4}$ Among respiratory tract strains biotype II predominated in Sweden" and in London. ${ }^{2}$ Our own experience is similar for strains isolated from groups 2 and 3 , but biotype II

Table 5 Relation between biotypes and serotypes of Haemophilus infuenzae

\begin{tabular}{llllllll}
\hline Biotype & \multicolumn{2}{l}{ Serotype } & & & & \multicolumn{2}{l}{ No tested } \\
\cline { 2 - 7 } & $a$ & $b$ & $c$ & $d$ & $e$ & $f$ & \\
\hline I & 0 & 13 & 1 & 1 & 0 & 0 & 41 \\
II & 0 & 3 & 3 & 1 & 0 & 0 & 46 \\
III & 0 & 2 & 0 & 0 & 0 & 0 & 22 \\
IV & 0 & 0 & 0 & 0 & 0 & 0 & 11 \\
V & 0 & 4 & 0 & 0 & 0 & 0 & 22 \\
NT & 0 & 2 & 0 & 0 & 0 & 1 & 10 \\
\hline NT = not typeable. & & & & & & &
\end{tabular}

strains were significantly less common among the cystic fibrosis group.

Three of the total of 11 strains of $H$ influenzae that did not fall into biotypes I-V (Table 1) fitted the group that has tentatively been designated biotype VI.' ${ }^{\prime}$ Four strains gave positive reactions with ornithine decarboxylase, indole, and $\beta$-galactosidase but were urease negative. Whether these should be classified as $H$ influenzae and designated biotype VII is debatable since $H$ influenzae is usually considered to be $\beta$-galactosidase negative. A problem also arises with the remaining four strains that were negative in all four tests. These are being investigated further.

$\beta$-lactamase production has been recorded as being more common among biotype I strains of $H$ influenzae compared with other biotypes. ${ }^{310}$ Similarly, a significantly higher incidence of $\beta$-lactamase production has been noted among capsulated compared with non-capsulated strains. ${ }^{9}$ In the present series, however, three of $31(9.6 \%)$ capsulated strains were $\beta$-lactamase producers compared with 11 of $121(9.0 \%)$ non-capsulated strains. Of more importance is the finding that of our $14 \beta$-lactamase positive strains of $H$ influenzae no fewer than seven were of biotype $\mathrm{V}$. Further investigation is required to determine whether there is any relation between particular biochemical properties and ability to produce $\beta$-lactamase. Relevant to this may be the evidence that suggests an inverse relation between urease and ornithine decarboxylase production and $\beta$-lactamase production among non-capsulated strains. This has been taken to indicate that noncapsulated strains producing both enzymes may, for some reason, be unable to acquire transposon $A$ determining lactamase production. ${ }^{9}$

$\beta$-lactamase production is much more common among strains of $H$ parainfluenzae. No fewer than $43 \%$ of positive strains were of biotype $I$, which represents $32.7 \%$ of all biotype I strains. The 17 biotype II strains of $\boldsymbol{H}$ parainfluenzae represents $38.6 \%$ of all positive strains and $21.7 \%$ of all 
biotype II strains. Within the cystic fibrosis group 13 of the $26(50 \%)$ biotype I strains were $\beta$-lactamase producers, the figure for biotype II being $27.9 \%$ of all biotype II strains. These are significantly greater than the percentage for biotypes I and II in the respiratory and control groups $(p<0.01)$. This may reflect selective antibiotic pressures within the cystic fibrosis group.

Capsulation was reported in 52 of $71(73 \%)$ biotype I strains, of which $45(63 \%)$ were type b, compared with only $12 \%$ for biotype II strains.' Similarly, 13 of 15 biotype I strains were of type b in the present series (Table 5). Significantly more capsulated strains were found in biotype I isolates compared with other biotypes. The relation between the presence or absence of capsulation and biotype is difficult to determine from published series since isolates reported have often been from cerebrospinal fluid and blood, where most are type b biotype I strains.

Since $H$ influenzae is one of the major pathogenic organisms in children with cystic fibrosis biotyping procedures may have an important part to play in epidemiological investigations. In particular, certain biotypes may have increased pathogenic potential irrespective of serotype and this may correlate with certain of the phenotypically expressed biochemical properties of the organisms. Such properties may reflect the presence of virulence factors other than capsule. It will also be of interest to determine whether any increase in the incidence of $\beta$-lactamase production among $H$ influenzae isolates is associated with a change in biotype distributions.
References

' Kilian M. A taxonomic study of the genus Haemophilus with the proposal of a new species. J Gen Microbiol 1976;93:9-62.

${ }^{2}$ Mehtar A, Afshar SA. Biotyping of Haemophilus using API 1OS - an epidemiological tool? J Clin Pathol 1983;36:96-9.

${ }^{3}$ Granato PA, Jurek EA, Weiner LB. Biotypes of Haemophilus influenzae: relationship to clinical source of isolation, serotype and antibiotic susceptibility. Am J Clin Pathol 1983;80:73-7.

4 Albritton WL, Penner S, Slaney L, Brunton J. Biochemical characteristics of Haemophilus influenzae in relationship to source of isolation and antibiotic resistance. J Clin Microbiol 1978; 7:519-23.

${ }^{5}$ Kilian M. A rapid method for the differentiation of Haemophilus strains. The porphyrin test. Acta Pathol Microbiol Scand $[B]$ 1974;82:835-42.

6 Kilian M, Sorensen I, Frederiksen W. Biochemical characteristics of 130 recent isolates from Haemophilus influenzae meningitis. J Clin Microbiol 1979;9:409-12.

7 Biberstein EL, Mini PD, Gills MG. Action of Haemophilus cultures on delta-amino-levulinic acid. J Bacteriol 1963;86:8149.

${ }^{8}$ Tsai WC, Wu JJ. Serotypes and biotypes and antibiotic susceptibility of Haemophilus influenzae encountered in a clinical laboratory in Taiwan. Chinese Journal of Microbiology 1979;12:140-8.

' Kamme C. Haemophilus influenzae: correlation between biotypes and beta-lactamase production. Acta Pathol Microbiol Scand [B] 1980;88:261-4.

${ }^{10}$ Goldberg R, Washington JA. The taxonomy and antimicrobial susceptibility of Haemophilus species in clinical specimens. Am J Clin Pathol 1978;70:899-904.

Requests for reprints to: Dr KC Watson, Central Microbiological Laboratories, Western General Hospital, Crewe Road, Edinburgh EH4 2XU, Scotland. 